\title{
The role of law in reproductive medicine: a new approach
}

\author{
David Jabbari University of Reading
}

\section{Author's abstract}

\begin{abstract}
It is a common feature of debates on the regulation of reproductive medicine to find law portrayed as a crude form of intervention consisting in the imposition of inflexible rules on doctors and medical researchers. This paper argues that this view must be replaced by a more accurate assessment of the law's potential role in the regulation of reproductive medicine. From an analysis of the White Paper on human fertilisation and embryology, and in particular the proposed Statutory Licensing Authority, the author contends that far from being an inflexible method of regulation law can foster discussion and compromise.
\end{abstract}

The quality of medical-ethical debate on human fertilisation and embryology is lowered by the prevalence of rudimentary conceptions of legal regulation. Such regulation is typically assumed to require the legislative imposition of inflexible rules in order to facilitate adjudication before the courts. Examples such as the 14-day limit on embryo research proposed by the Warnock Committee (1) and the restrictive clause of the recent White Paper (2) which, if accepted by Parliament, would outlaw embryo research altogether, are understandably seen by the medical profession as instances of the law's inflexibility. The possibility that law could be a more flexible vehicle for compromise and accommodation of the relevant interests is rarely explored.

It is helpful to distinguish three forms of legal regulation which can be applied to the context of human fertilisation and embryology: the formal, the substantive and the reflexive (3). These forms are descriptive terms developed by sociologists of law to characterise rival methods of legal control of social life. While the rudimentary view of legal regulation described above corresponds to the concept of substantive legal regulation, reflexive legal regulation offers novel perspectives in the area of human

\section{Key words}

Reproductive medicine; human fertilisation; embryology; Statutory Licensing Authority; legal regulation; law and medicine. fertilisation and embryology. More generally, it is to be hoped that a greater contribution from the sociology of law will result in ever more refined accounts of the potential role of law in medical ethics.

The conventional view: formal and substantive legal regulation

Substantive legal regulation characterises the pattern of legal intervention into social life accompanying the rise of the modern welfare state (4), and is to be distinguished from its antecedent, formal legal regulation. The main characteristics of formal legal regulation can be listed: the pursuit of individual autonomy by the establishment of legal rights to liberty and private property; the creation of the conditions for the mobilisation and allocation of resources in a free market society; and the rigorous application of legal rules regardless of the consequences of such application on the social distribution of wealth. The classical law of contract is often cited as a paradigmatic instance of formal legal regulation, since the aim of the law was to generate fixed rules which sanctified commercially fruitful acts of private exchange. Instances of injustice, for example a severe lack of equality in bargaining power between the parties to a contract, were not permitted to undermine the existence of legal obligation. By contrast, there are three main features of substantive legal regulation.

Firstly, the emphasis of substantive legal regulation is on detailed regulation of social life rather than the promotion of individual autonomy: the aim of the law is not simply to facilitate market transactions. Substantive legal regulation attempts to subject market transactions to considerations of social policy, fairness and justice. For example, since the beginning of this century we have seen the proliferation of various implied and non-disclaimable terms into contracts for the sale of goods to ensure that goods sold to consumers are of merchantable quality and fit for their purpose (5). Occasionally, certain classes of transaction are prohibited altogether; for example, markets in babies, wombs and organs, forbidden by the Adoption Act 1976, the Surrogacy Arrangements Act 1985, and the Human Organ Transplants Act 1989 respectively. The effect of both these trends is a more interventionist role for the state in social life, whereby legal norms are 
injected into areas previously unregulated by law and inadequacies in the market are compensated for by the imposition of collective standards.

Secondly, substantive legal regulation represents a movement away from general permissive or prohibitory rules to more particularised rules and standards (6). This allows the law to be tailored to the needs of particular groups and contexts. Hence, broad rules of contract and tort are increasingly supplemented by rules and procedures specific to consumers, doctors, employees, companies, administrators etc. Similarly at the level of legal reasoning, awareness of inequalities in market power results in a tendency for judges to mitigate the harshness of a rigorous application of rules by the use of discretionary standards. The classical insistence that a legal contract be performed once agreement between the parties has been secured, for example, is hedged about by a series of excuses which negate this duty: for example that the plaintiff has suffered misrepresentation or has been unduly influenced by the defendant. These so-called 'excuses' cannot be separated from a substantive standard of fairness or justice. Again, the law is imposing a standard of proper conduct.

Finally, substantive legal regulation focuses on the results of legal intervention: a given result is desired from the onset of legal regulation. In pursuance of this, the executive generally does not permit self-regulation except where structures exist to enable the executive to influence the behaviour of regulatory agencies (7). These structures take a variety of forms ranging from legislation, written circulars and policy guidance to reliance on the courts as a control mechanism. Rather than enforce the outcome of the autonomous bargaining of parties or interest groups, the law is employed to modify or supplant this. Further, a restricted right of any citizen to take legal action on behalf of the public means that the influence of interest groups in the legal process is similarly restricted (8).

The key distinction between formal and substantive legal regulation is the interventionist and policyoriented character of the latter. Developments in human fertilisation and embryology are clearly too recent to have developed in the laisser-faire environment of formal law. From the beginning governments, influenced by the ethical dilemmas involved, have viewed this area, albeit belatedly, as one worthy of the most detailed legislative regulation (9). The dominant image of the law in this area is accordingly very close to the model of substantive legal regulation. That is, as essentially interventionist and result-oriented, enforcing collective standards through inflexible rules such as the prohibition of commercial surrogacy and the proposed ban on embryo research.

\section{A new approach: reflexive legal regulation}

Critics, particularly members of the medical and scientific community, have attacked substantive legal intervention in reproductive medicine as being too crude to deal flexibly and informally with the complexity of modern scientific conditions (10). Whilst it seeks an ethical criterion, substantive legal regulation places restrictions on behaviour which are thought to act as a disincentive to scientific progress. For example, the proposal in the White Paper that would, if accepted by Parliament, make it a criminal offence to carry out any procedures on a human embryo other than those aimed at preparing the embryo for transfer to the uterus of a woman, is criticised by scientists as being likely to hold up valuable research into, for example, improving the treatment of infertility, gaining further knowledge about factors leading to congenital disease, developing more effective forms of contraception, and research on the detection of gene or chromosome abnormalities in pre-implantation embryos (11). Further, the rule form is criticised for its inability to regulate subject matter which does not fit into neat legal categories, such as the beginning and end of life in contexts such as abortion, euthanasia, and embryonic research. The proposed 14day limit on embryonic research of the Warnock Committee, and the 28-week limit on abortion are viewed as rather arbitrary attempts to satisfy the appetite of lawyers for rules.

The failing of the critics is to equate legal regulation per se with this inflexibility. In reality, it is possible to identify and promote an alternative conception of legal regulation which unlike substantive legal regulation does not regulate the detailed content and consequences of legal transactions, but instead restricts itself to the installation, correction, and redefinition of procedures and institutions which foster democratic self-regulation (12). This conception is called reflexive legal regulation and derives from the work of the German sociologist of law, Gunther Teubner. Reflexive legal regulation represents the highest stage of existing legal evolution and promises to remedy many of the defects in substantive legal regulation. Specifically, it seeks to make social institutions more responsive to processes of autonomous social development while at the same time ensuring that the law has the capacity to regulate the complexity of modern social conditions. I turn now to describe the characteristics of reflexive law.

Firstly, the emphasis of reflexive law, like formal law, is upon procedure rather than substance. It aims to create procedures and institutions in different areas of social life which would govern the way in which discussion takes place and decisions are made. Reflexive law rejects the kind of interventions into social life which characterise substantive legal regulation, such as terms implied into contracts by statute or inflexible time-limits for embryonic research. It is an indirect form of legal control rather than a direct one, not seeking to achieve certain results. Reflexive law avoids an obsession with regulatory detail and concerns itself only with the overseeing of quasi-voluntary regimes, which are themselves constructed to foster public and expert participation. 
The legitimacy of reflexive law is therefore not connected to a set of substantive values, such as morality or fairness, but rather derives from its quest to enhance the procedures of legal and public decisionmaking: 'since ultimate grounds can no longer be made plausible, the formal conditions of justification themselves obtain legitimating force' (13).

The second characteristic of reflexive law is that it aims to encourage democratisation of legal decisionmaking mechanisms (14). Rather than simple majoritarian democracy, reflexive law demands consensus on the basis of public and expert participation. This is achieved by the establishment of institutions which can facilitate this form of participation. Debate over subsance is therefore replaced by debate over the terms of discourse, the most important issue being the prevention of a professional hegemony (15). However, the law need not have any role in imposing democratic mechanisms on public institutions: the emphasis is upon selfregulation and self-democratic organisation. This overcomes the problem of using law where it is ineffective or works by destroying traditional patterns of social life.

Finally, reflexive law has an important role to play in regulating the complexity of modern social life (16). Contemporary legal theorists such as Luhmann (17) have argued that as society evolves the degree of its complexity increases and hence, the legal system must develop yet more adequate means of regulating this complexity. According to Luhmann, the evolutionary potential of a legal system will be measured by the extent to which its institutions can accommodate rapid social and technological change. Reproductive medicine is a prominent example of rapid technological change necessitating both changes in existing law, for example inheritance, parenthood and divorce, and requiring the creation of laws to deal with totally novel situations such as surrogacy and embryology. Legal systems based upon comparatively . simple organisational principles, notably legal systems with a high religious or moral content, would embody legal structures with too low a degree of complexity reduction to accommodate modern reproductive science. A high level of internal regulated complexity in law will involve allowing alternatives, possibilities of variation, dissent and internal conflicts (18). It is the case therefore that a tolerable degree of indeterminacy in legal institutions is an achievement not a mishap (19). It is this feature of reflexive law which is I think most promising in the context of reproductive medicine.

As outlined the concept of reflexive legal regulation is highly abstract. Although the last characteristic of reflexive legal regulation described above is prescriptive, there are some areas which already display the reflexive potential of law and will therefore assist in making the concept more concrete. The legal regulation of collective bargaining provides one such example. Here the traditional approach of the law is not to seek to determine specific outcomes to disputes, but rather to shape the organisation of collective bargaining by defining procedures and creating institutions which allow autonomous bargaining between employers and employees. In procedural terms, the law emphasises self-regulation by declining to enforce collective bargains (20), recognising that this may be either ineffective or destroy the understandings of the parties to the collective bargain. In institutional terms, the law provides machinery, such as ACAS which facilitates voluntary methods of labour conciliation and arbitration. The membership of bodies such as ACAS combines expert and lay participation to ensure that expert opinion is tempered by considerations of the public interest.

\section{The legal regulation of human fertilisation and embryology}

The concept of reflexive legal regulation offers refreshing perspectives in the area of reproductive medicine. The complex nature of both the scientific techniques and the ethical dilemmas makes the crude rule imposition of substantive legal regulation an inappropropriate method of regulating this area. The role of law should be to establish procedures and institutions through which expert and public opinion can mould policy. It is not sufficient to have interestgroup representation in the legislative process or in ad hoc committees such as Warnock. Rather the whole process of legal regulation in this area must be continually responsive, or 'reflexive' to changes in medical technology and in public opinion.

Interestingly, the recent White Paper's plans to create a Statutory Licensing Authority (SLA) to regulate the area of human fertilisation and embryology possess potential in this respect (21). The concept of reflexive legal regulation therefore provides the best means by which to evaluate what will be the central institution in this area. Three questions stand out. Firstly, how should the law set the terms of the debate which the SLA will conduct? Secondly, do the arguments for the reflexive approach of the SLA engendered by the ethical dilemmas in the general area of reproductive medicine, apply equally to the contexts of embryonic research and infertility treatment? Thirdly, will the structure and character of the SLA be such as to allow genuinely 'reflexive' legal regulation? After describing the proposed SLA, I shall deal with these questions in turn.

The SLA will replace the Voluntary Licensing Authority that was established in 1985 by the Medical Research Council and the Royal College of Obstetricians and Gynaecologists. The functions of the SLA will be the licensing of those providing infertility services involving IVF, AID, and egg or embryo donation; those storing human embryos and gametes; those engaged in the diagnostic use of techniques involving the penetration of a non-human ovum by human sperm; and those undertaking research on 
human embryos (22). The SLA will also advise ministers on medical and scientific developments in the fields of infertility, collect data on facilities available for the provision of those infertility treatments it regulates, provide guidance to the medical profession on good practice in the areas for which it is responsible, and maintain a register of information about gamete/embryo donors (22). The SLA will be able to develop its own policies on who should be licensed, subject only to minimum standards of administrative efficiency on the part of the licensee (23). It will be a criminal offence to create an embryo outside the body, or one inside the body by the use of donated gametes, without an appropriate licence from the SLA (24).

Beginning with the first question mentioned above, the terms of the debate which the SLA will conduct, one of the key features of reflexive legal regulation is to promote procedures and institutions which allow interest groups to discuss and make law. The parameters of the SLA's rule-making powers are therefore very significant. While the White Paper proposes to criminalise genetic manipulation of the embryo, the creation of hybrids and trans-species fertilisation (25), MPs will be given the chance to vote on either a permissive or prohibitive draft clause in relation to embryonic research and experimentation for inclusion in the forthcoming Bill (26). Both will allow the use of embryos for implantation, but the prohibitive clause would allow only this whereas the permissive clause would allow in addition projects licensed by the SLA. Such projects are defined in para 35 as those designed 'to bring about advances in diagnostic or therapeutic techniques, or in fertility control'. While absolutists will balk at the destructive use of embryos to bring about advances in contraception, the merit of the permissive clause is that it establishes a basis for discussion and possible working compromise. The clause therefore finds justification in the concept of reflexive legal regulation. Since the arguments of the scientists are entitled presumptively to as much respect as the absolutists, there seems no good reason why the terms of the institutional debate should be loaded to the absolutists' side, as would be the case if the prohibitive clause were carried.

The second question I wish to discuss is whether the reflexive approach of the SLA should apply equally to embryonic research and infertility treatment. It is clear that areas involving such complex and contentious issues as that of human fertilisation and embryology cannot be regulated by the simple solutions of substantive legal regulation. A substantive imposition of rules is unsuitable both where the law is dealing with processes such as the beginning and end of life, and where there is a disagreement over fundamental ethical principles. It is questionable whether the arguments for the SLA generated by the ethical dilemmas inherent in embryonic research apply equally to the area of infertility treatment. While the publication of the recent White Paper need not provide the occasion for a complete re-examination of the ethical issues raised by these techniques, it is clear that in the wake of these innovations, images of horror at 'test tube babies' have clouded the legal debate. Techniques designed to treat the invidious effects of infertility have on occasion been conflated with those which have a morally contentious goal: to extend the frontiers of science. The White Paper is not completely free of this confusion; both types of techniques are described as raising 'fundamental ethical questions' (27) hence a formidable regulatory framework is to be directed not just at embryonic research but at any technique which features a doctor, a potential fetus and a mother.

I believe there is a fundamental difference between the ethical issues raised by embryonic research and infertility treatment, and that this has implications for the proper form of legal regulation. Whereas in the area of embryonic research ethical theories concerning the right to life and the definition of personhood are invoked, in the area of infertility treatment objections of a lesser character are encountered: objections more of social policy than ethical principle. Consequently, it is only in the area of embryonic research that we encounter fully developed and self-consistent ethical theories conflicting with each other, producing dilemmas in which those ethical theories can justify two opposing courses of action. Significantly for the reflexive law thesis morality cannot be employed to choose between these courses, hence the search for an ideal rule is misplaced. Let me explain this point more fully.

The area of embryonic research features moral absolutes regarding the status of human beings. The absolutists feel that the embryo is a full human being and as such is inviolable. Their basic argument is that an embryo has the potential to develop into a living person and is thus unlike semen or eggs (28). This potential for human life means that the embryo should be regarded as fully human and thereby entitled to the right to life. Those who deny that an embryo is a person do so on many grounds (29). They ask how a fertilised egg can be considered a new individual when it could become two individuals, ie twins. Some objectors state that just because something has the potential for $\mathrm{X}$, this is not a reason for treating it as if it had already become $X$. In the light of these fundamental disagreements, it would be wise to treat the Warnock Report's limit as an index of the relative strengths of the scientific and absolutist lobbies. Because moral absolutes are invoked, it is not possible to discover a single correct criterion. It is this which undermines substantive legal regulation and the rule form in this context.

By contrast, the objections raised against infertility treatment, such as the adultery, masturbation and unnaturalness objections (30), are non-absolute, frequently inconsistent, and arguably rebutted by a presumptive ethical duty to overcome childlessness (31). An example of the weakness of one of these 
arguments will be sufficient to illustrate this point. The unnaturalness objection (32) to artificial insemination (AI) for example, states that AI severs the link between procreation and sexual intercourse. Such an objection places a high moral value on the natural order of biological processes; the natural order being defined negatively as that which is untouched by human intervention. Even before analysing the objection, it can be asked whether it has any normative significance: it is clearly fallacious to equate the 'natural' with the 'good'. The non-absolute nature of the objection is also clear. Firstly, if by 'natural' is meant all that happens in nature untouched by human intervention, practically all forms of medical treatment would have to be rejected (32). This cannot be the intention of those who hold this view. Secondly, is the human suffering permitted in order to avoid acting unnaturally ethically justifiable? Clearly it is not. The inconsistency in this objection therefore is that it leads to conclusions its proponents could not support. A similar degree of internal inconsistency weakens the adultery and masturbation objections (33). While embryonic research remains a heated issue, the question of whether or not to provide infertility services is not a question that the government need consider (33).

Accordingly, the value of reflexive legal regulation is highest in the context of embryonic research. In this area we cannot appeal to substantive moral values, for agreement is not simply absent but is denied by the conflict of ethical theories. The best that can be achieved is compromise. The aim of the law in the regulation of embryonic research should be to create both institutions which are a forum for informed discussion, and procedures which can promote compromise. In the area of infertility treatment, the weak nature of the objections should imply a very mild form of regulation. Discussion must clearly take place on an administrative framework for the provision of infertility services but the state is not justified in subjecting access to such services to onerous conditions. Yet the envisaged scope of the SLA's functions are clearly wider than this.

The functions of the SLA derive from its remit; namely, to 'regulate and monitor practice in relation to those sensitive areas which raise fundamental ethical questions'. This is taken by the White Paper to include 'treatments involving the use of donated gametes (for example AID) or donated embryos (34). If the above argument is correct, it is false to state that such treatments involve fundamental ethical issues. This is not to say that they should not be within the remit of the SLA, but the White Paper should have made it clear that they are covered only because qua medical techniques, they can give rise to the possibility of research on embryos. That is to say, the techniques of super-ovulation employed in IVF provide the surplus embryos which service the experimenters. A clearer statement would have removed the possible conflation of techniques with very different ends. More importantly however, a sharper demarcation would serve to restrict the SLA's licensing jurisdiction to issues related to unauthorised creation of embryos, control of number of sperm donations etc. By conditional licensing of infertility services, the SLA will take away from individual practitioners the decision about whether, for example, single women or lesbian couples should be allowed access to AID. The SLA is to be able to adopt a blanket policy on access to infertility treatment. Furthermore a limited appeals procedure and the inefficacy of administrative law will not permit an effective challenge by a practitioner refused a licence for failure to comply with SLA policy.

The dangers of administrative discretion in this area are illustrated by an examination of the case of $R v$ Ethical Committee of St Mary's Hospital ex p Harriott (35), in which a married woman was refused access to IVF, on the grounds that she had a criminal record, including convictions for allowing premises to be used as a brothel and soliciting for prostitution. These convictions had caused the applicant to be refused by adoption agencies when she had sought children in the past. The worrying feature of the case is that only after a protracted battle with the consultant was the applicant informed of the actual reason for refusal, the prior refusal by adoption agencies. In fact she had been told that IVF was impossible because of a defect in her husband's semen. Interestingly, Schiemann $\mathrm{J}$ in the Divisional Court held that the decisions of a consultant or local ethical committee could be subject to judicial review but that neither had acted unfairly in this case. This was in spite of the fact that the applicant was not given an opportunity to put evidence and submissions before the ethical committee when it had considered her case. The overriding worry is clearly the arbitrariness of making decisions on such grounds in the context of reproduction. The capacity to have offspring is not allocated by nature according to suitability as a parent. One can only really determine whether a parent is unfit after the child is born. In such a situation, do not care and wardship proceedings exist to determine this and therefore protect the child? Further it is false to draw analogies between adoption and infertility treatment, since the latter can quite fairly be seen as a treatment for illness which the relevant health authority was under a statutory duty to provide.

Turning to our final question, on the assumption that the permissive clause is carried, the important point will be the composition of the SLA. Since I have argued that the ethical dilemmas posed by embryonic research can be resolved only by reflexive institutions employing informed discourse, representation of the relevant interest groups is necessary. This model of 'interest group pluralism' will allow working compromises to be reached over the extent of permitted research. The proposed SLA partially enshrines such an approach. Paragraph 16 of the White Paper makes it clear that the legislation will provide for varied representation. The SLA will be independent of government, have a lay chairman, and a membership 
with wide-ranging interests (including the fields of law, nursing, social work, philosophy and religion as well as medicine and science) including a substantial lay representation. This reflexive approach to licensing, while clearly nothing new, is to be particularly welcomed in this context. Yet, complacency must not set in. As Lee has shown in his analysis of the Warnock Committee, little debate went into selecting the membership of that committee (36). The challenge of reflexive legal regulation is to devise procedures which can draw upon the widest range of expertise without the effective 'capture' of the SLA by professionals (37). The White Paper should have made the avoidance of such capture a central legislative theme.

\section{Conclusion: qualified liberalism}

The argument of this paper has been threefold. Firstly, it has argued that it is necessary to move beyond the simplistic view of legal regulation which has led to impoverished notions of the law's potential in the context of reproductive medicine. Secondly, the concept of reflexive legal regulation has been advocated as the appropriate form of regulation in this area, offering to remedy much of the inflexibility of substantive legal regulation. Finally, it has been argued that, due to the lack of fundamental agreement on the ethics of embryonic research, the principal use of reflexive legal regulation should be in that area. By contrast, there are no compelling reasons why regulation of infertility treatment should be so extensive as to include decisions on access to infertility treatment.

The overall conclusion therefore must be the advocacy of a qualified liberalism for the legal regulation of reproductive medicine. The qualification is a democratic one and requires all decisions of medical experts to withstand the scrutiny of public opinion. It is this qualified liberalism which underlies both the proposed SLA and the demand for permissive laws in the context of infertility treatment. Institutional liberalism in embryonic research implies compromise on the basis of expert and public opinion in the SLA. Permissive laws, supplemented by control of gamete donations and unauthorised creation of embryos represent the correct balance between the state and the individual interest in the area of infertility treatment. The merit of reflexive legal regulation is that it demonstrates the law's capacity to be a repository for discussion. All too often the law is seen as the end of discussion. It is to be hoped that when moral absolutism is put on one side, imaginative and workable solutions will emerge to problems thought previously to require the hand of Leviathan.

David fabbari LLB BCL (Oxon) is a Lecturer in Law in the Department of Law at the University of Reading.

\section{References}

(1) Report of the Committee of Inquiry into Human Fertilisation and Embryology. Cmnd 9314. HMSO, 1984. Para 11.22. Hereafter referred to as the Warnock Report.

(2) Human Fertilisation and Embryology: A Framework for Legislation. Cm 259. DHSS, 1987. Para 30. Hereafter referred to as the White Paper.

(3) This typology is taken from Teubner G. Substantive and reflexive elements in modern law. Law and society review $1983 ; 17: 239$.

(4) Cotterell R. The sociology of law. London: Butterworths, 1984; see also Unger R M. Law in modern society. New York: Free Press, 1976.

(5) Collins H. The law of contract. London: Weidenfeld \& Nicolson, 1986: Ch 2.

(6) See reference (4): 172-174.

(7) Baldwin R, McCrudden C, eds. Regulation and public law. London: Weidenfeld \& Nicolson, 1987: Chs 1-4.

(8) Gordon R. The Independent 1988 Jun 17:16.

(9) Warnock M. A question of life. Oxford: Blackwell, 1985: xv-xvi.

(10) See reference (2): note 3, annex B.

(11) See reference (2): para 30 and annex $B$.

(12) See reference (3): 245-246.

(13) See reference (3): 269.

(14) See reference (3): 255-256.

(15) Jacob J. Doctors and rules. London: Routledge, 1988.

(16) See reference (3): 262-264.

(17) For an introduction to the work of Luhmann see Murphy W T. Niklass Luhmann on law and social theory. Modern law review 1984; 47:603.

(18) See reference (17): 604.

(19) See reference (17): 605.

(20) See Ford Motor Co $v$ Amalgamated Union of Engineering and Foundry Workers [1969] 2 All ER 481.

(21) See reference (2): paras 9 to 27.

(22) See reference (2): para 15.

(23) See reference (2): paras 20 to 25.

(24) See reference (2): para 27.

(25) See reference (2): paras 39 to 41.

(26) See reference (2): para 30.

(27) See reference (2): para 2.

(28) See reference (2): annex B.

(29) See Harris J. In vitro fertilisation: the ethical issues. Philosophical quarterly 1983; 33:217.

(30) See reference (1): paras 4.10-4.14 and 5.6-5.8.

(31) Feminist authors deny the existence of this duty on the ground that it stigmatises infertility. See Stanworth $M$, ed. Reproductive technologies. Oxford: Polity, 1987.

(32) Singer P, Wells D. The reproduction revolution. Oxford: OUP; 1982: 40-50.

(33) Jabbari D. The ethics of infertility treatment and embryonic research: implications for legislation. Northern Ireland legal quarterly 1988; 39:402.

(34) See reference (2): para 13.

(35) 137 New law journal 1038.

(36) Lee S. Re-reading Warnock. In: Byrne P, ed. Right and wrongs in medicine. London: King's Fund Institute, 1986.

(37) On the concept of 'capture', see reference (7): 9-11; 198199. 